\title{
Correction to: A Contingency Model in Establishing Brand Loyalty: Relationship Age as a Moderator
}

\author{
Chao-Chin Huang ${ }^{1} \cdot$ Chung-Yuan Tsay ${ }^{1} \cdot$ Shih-Chieh Fang $^{2} \cdot$ Shyh-Ming Huang ${ }^{3}$
}

Published online: 5 January 2022

(c) Springer Nature Limited 2021

\section{Correction to: Corporate Reputation Review} https://doi.org/10.1057/s41299-021-00131-7

Due to an unfortunate mistake the affiliation of Chung-Yuan Tsay has been given erroneously. It should read:

Department of Agribusiness Management, College of Management, National Pingtung University of Science and Technology (NPUST), No. 1, Shuefu Road, Neipu, Pingtung 91201, Taiwan, ROC.

The original article has been corrected.

Publisher's Note Springer Nature remains neutral with regard to jurisdictional claims in published maps and institutional affiliations.

The original article can be found online at https://doi.org/10.1057/ s41299-021-00131-7.

Chung-Yuan Tsay

cytsay@mail.npust.edu.tw

Chao-Chin Huang

cchuang2019@mail.npust.edu.tw

Shih-Chieh Fang

fangsc@mail.ncku.edu.tw

Shyh-Ming Huang paulh@stust.edu.tw

1 Department of Agribusiness Management, College of Management, National Pingtung University of Science and Technology (NPUST), No. 1, Shuefu Road, Neipu, Pingtung 91201, Taiwan, ROC

2 Department of Business Administration, National Cheng Kung University, No. 1, University Road, Tainan City 701, Taiwan, ROC

3 Department of Marketing and Logistics Management, Southern Taiwan University of Science and Technology, No. 1, Nan-Tai St., Yung-Kang District, Tainan City 710, Taiwan, ROC 